Article

\title{
The Role of Policy Champions and Learning in Implementing Horizontal Environmental Policy Integration: Comparative Insights from European Structural Fund Programmes in the U.K.
}

\section{Tony Gore}

Centre for Regional Economic Social Research, Sheffield Hallam University, City Campus, Sheffield S1 1WB, UK; E-Mail: t.gore@ shu.ac.uk; Tel.: +44-114-225-3561; Fax: +44-114-225-2197

Received: 15 April 2014; in revised form: 1 August 2014 / Accepted: 5 August 2014 /

Published: 22 August 2014

\begin{abstract}
This paper examines attempts to integrate environmental sustainability goals into the design and implementation of projects funded by the EU Structural Funds programmes in the U.K. between 2000 and 2006. It does so by comparing how the two "horizontal priorities" (environmental sustainability and gender equality) fared in terms of understanding and acceptance by project applicants. It places this material within the wider context of literature on environmental policy integration and inter-agency cooperation. A "policy coordination" framework is used as a heuristic device to construct an account of the ways in which the two themes were handled through the interplay of the myriad of actors and organisations involved in the process. A key part in this involved the deployment of "policy champions" to work with external organisations bidding for funding to support projects that formed the core of programme implementation. The paper also examines the variable reactions on the part of project designers to the requirement to incorporate environmental and gender goals and the greater inter-professional networking that these implied. The comparison between the two priorities clearly demonstrates the difficulties inherent in the breadth and complexity of environmental issues and the need in the first instance to link them to relatively simple actions directly associated with economic development activity. The study concludes that this is essentially the first step in a more protracted "policy learning" process.
\end{abstract}


Keywords: policy coordination; policy champions; environmental policy integration; European Structural Funds; horizontal priorities

\section{Introduction}

An enduring feature of public administration is the difficulty faced by conventional models of government in incorporating "wicked issues", or problems that "defy efforts to delineate their boundaries and to identify their (exact) causes, and thus to expose their problematic nature" [1] (p. 167). These issues include unequal distribution of wealth and economic opportunities ("social inclusion"), relations between different social groups ("community cohesion") and protection of the natural environment, while ensuring economic prosperity ("sustainable development"). All have manifest relevance for most policy domains, from macro-economic steering through social policy and sub-national economic development to labour market activation. In bridging jurisdictional, organizational and professional boundaries, they require actions that are contrary to conventional ways of policy-making, a commitment to building inter-organizational capacity, an emphasis on relationships and interdependencies and the development of appropriate interpersonal skills [2].

Unsurprisingly, policy makers and practitioners have often struggled to find ways of incorporating such "external" considerations into actions designed to address their own specific concerns. Inevitably, any attempt to address "wicked issues" in mainstream programmes raises acute questions about the boundaries around disciplinary knowledge and professional practice. Despite the difficulties encountered in trying to imbue the myriad parts of government with an appreciation of, and a response to, the implications of these issues, policy has continued to set public bodies with the task of persuading external agents to address them, as well.

Environmental concerns are perhaps the classic exemplar of such dilemmas and conflicts, and the integrative approach has been a hallmark of many policies designed to tackle them. These concerns have escalated in recent years, with growing alarm at global climate change, emphasising the need for people and organisations in all walks of life to contribute to both adaptation and mitigation mechanisms. An important aspect of this more local integrative working has involved persuading other public bodies, private firms and voluntary sector organisations to work towards embedding sustainable actions into their everyday ways of operating. In the business world, this process is often referred to as "corporate greening".

The expanding literature on this topic focuses particularly on what companies do and how they do it. Attention has been given to matters such as changes to products and processes [3], environmental training for staff [4], reductions in energy consumption and waste [5] and procurement of goods and services [6]. Case studies illustrate that full integration of sustainability into an organisation's core operating model may take many years [7]. Several studies have explored the reasons why businesses adopt such practices, as well as assessing the barriers that prevent others from doing so. The mix of drivers has both internal and external sources. The former involve matters such as competitive advantage, enhanced reputation, cost savings and the presence of committed individuals or "sustainability leaders", whilst the latter include media exposure and compliance with legislation and 
government regulations [8]. However, much less impact has been found with regard to softer, more persuasive influence on the part of stakeholders (customers, partners, government bodies). Here, it must be acknowledged that only a minority of organisations have yet adopted greening strategies, with most businesses readily admitting that they lack any effective environmental policy [9-11].

There is a distinct "research puzzle" here. Given that encouraging business firms to adopt more environmentally benign practices has been an enduring strand of government policy for nearly twenty years, what processes act to promote changes in this direction and what constraints serve to hinder such attempts? Certainly, whilst our knowledge of public practice and corporate response in this field has grown considerably in recent years, it remains incomplete, particularly in terms of the role of key actors within the process. This article aims to make a modest contribution to this important body of knowledge. Its main purpose is to examine the issues involved when a public programme using "soft" policy measures seeks to promote "greener" ways of working amongst those receiving grants that are allied to a range of economic development programme aims, and the role that key personnel play at various points in this process. It does this through a comparative analysis of EU Structural Fund programmes in the U.K. during 2000-2006.

The Structural Funds form a central part of the EU cohesion policy. Their primary focus is on the economic and human capital improvement of less prosperous regions that qualify for such support. Traditionally programmes have emphasised matters like wealth creation, business growth and innovation, product marketing, employment generation and increased competitiveness. In their regional form, they have operated since the mid-1970s. Before the 1990s, the focus was squarely on infrastructure improvement and business development, but it became increasingly clear that regional prosperity hinged on associated social and environmental issues as much as these economic factors. This realisation coincided with the growing push for environmental policy integration in all policies overseen by the European Commission (EC). While the 1994-1999 period programmes were required to address "sustainability and environmental protection" and "gender equality" as "central considerations" [12,13], the subsequent 2000-2006 programme promoted both to the status of "horizontal priorities" (HPs). These became a formal regulatory requirement of programme design [14].

In essence, HPs may be aligned with "mitigation" actions that serve to lessen environmental impacts of existing operations, in contrast to "adaptation" approaches, which seek to reconfigure production methods and processes; often receiving direct financial support, these then form part of the "vertical" strand of the programmes. While economic experts and business interests might recognize the broad merits of complex environmental arguments on the one hand and "softer" social science evidence around gender inequality on the other, the strongly economic ethos of the Structural Funds could make it more difficult to discern ways of meeting "unconventional" environmental goals via standard development projects than for gender-related improvements. Thus, an important question is whether progress with environmental goals, like a reduction in gender inequality, is compatible with a model whose primary aim is transformational economic change in a specified geographical area. Thus, this article traces the trajectory of the two HPs from their incorporation into the Structural Funds at the EU level through to their implementation via regional programmes in the U.K. between 2000 and 2006. The contrasting nature of the two strands suggests that a comparison between them can shed useful light on the research puzzle outlined above, and can offer insights about the nature and prospects of this integrative approach for environmental sustainability. In other words, the comparison 
is drawn at two levels: firstly, between different regional programmes across the U.K.; and secondly, between the two HPs themselves.

The empirical analysis follows a broad framework devised by Peters [15] to mould together the steps involved in the process of policy coordination. This is used as a heuristic device to bring structure and order to the presentation of the findings. Within this, the analysis further draws on insights and concepts from the literature on policy diffusion, innovation and integration, on the one hand, and issue framing, policy entrepreneurs and inter-professional practice on the other. In particular, the article explores the role of key personnel acting as policy advocates or "champions" and their role in trying to present environmental and gender issues in ways that chime more readily with actors more attuned with the realities and language of economic development. The variable nature of these processes had a marked influence on the responses of organisations involved in designing and implementing projects funded by the Structural Funds programmes.

The paper is organized into four sections. The first explores the emergence of "environmental policy integration" (EPI) in the EU, linking this to the wider literature on policy bargaining, issue framing, the role of champions and inter-professional practice. A shorter second section outlines Peters' "policy coordination" model to act as a guiding framework for the subsequent presentation of the empirical material and sets out the information sources used. The third section then traces the initial framing of the sustainability and gender priorities at the EU level as part of the Structural Funds rubric, whilst the fourth assesses their implementation in the U.K. between 2000 and 2006. The final section concludes with observations concerning the variable nature and results of the bargaining processes and the role of champions in terms of the comparative environmental and gender aspects of project design, along with broader remarks on the utility of linking Peters' policy coordination framework with other insights from the literature for future implementation research on EPI.

\section{EU Environmental Policy Integration in Context}

\subsection{Environmental Policy Integration in the EU}

The pervasiveness of environmental sustainability issues in all areas of economic and social life has long been recognised by both politicians and policy-makers; the challenge has been to find ways in which this can be reflected in long-standing policy domains. In the EU, the approach taken has involved a growing commitment to "environmental policy integration" (EPI). This first emerged in the Third Environmental Action Programme [16], which proposed using the Structural Funds to support the development of cleaner technologies, especially in energy and transport. This was extended to other types of projects in the Fourth Environmental Action Programme [17]. A fully comprehensive version of EPI then formed the core of the Fifth Environmental Action Programme [18], calling for sustainable development principles to be incorporated into all policies overseen by the European Commission (EC) (see also [19]). Following this, sustainable development and EPI were given a legal basis through their inclusion in Articles 2 and 6, respectively, of the Treaty of Amsterdam 1997, with EPI given further legitimacy in being declared "a chief concern" at the European Council meeting at Cardiff in 1998 and the establishment of the "Cardiff process" of high-level progress review. 
Although this commitment demonstrated agreement over the need for changes to economic processes and practices in order to improve environmental quality and human welfare, there was less clarity over how this might be achieved [20]. Consequently, the Sixth Environmental Action Programme [21] introduced several "forms of environmental capacity building", such as working in partnership with business and encouraging voluntary action by industry, as a way of connecting policy makers and practitioners with those perceived as capable of making a difference [22] (p. 224). Similarly, the EU Strategy for Sustainable Development argued for all societal groups and levels of government to be involved, stressing the need for "widespread ownership of the strategy by individuals, businesses, civil society and local and regional authorities." [23] (p. 15).

Lafferty and Hovden [24] distinguish between two types of EPI: the first involves a prioritisation of sustainable development (SD) considerations above sectoral interests; the second is the incorporation of environmental policy goals into existing decision-making processes to make them more comprehensive and, therefore, to improve their rationality. In the main, the focus has been on this second "transitional" form, involving "a cooperative process that should result in the penetration of SD and EPI into all sectors of society and public policy." [25] (p. 22). As part of this EPI has a key role as "an autonomous normative principle to reconcile economic development with the protection of the environment... (This) implies a highly reflexive form of problem-solving (and) the adoption of a new governance style... (It) is about the introduction of organisational structures, channels and procedures that facilitate a dialogue across policy sectors and governmental levels to reconcile conflicting interests and policy objectives" [25] (pp. 23-24).

The intrinsic link between this approach and deliberative practices involving a full range of partners in negotiation processes clearly encourages widespread experimentation around the means to resolve norm conflicts. This, in turn, depends on those involved opening up both cognitive and institutional boundaries in a process of "policy learning". Lenschow [25] (p. 29) has commented how under the Cardiff process, the development of indicators, the sharing of "best practices" and regular reporting commitments have provided an "authoritative context" for a "learning process towards 'greening' sectoral policies." Such policy learning can arise through direct experience ("lesson drawing"), from the experiences of others ("diffusion"), exposure to new information or technological developments. These mechanisms may require a skilled activator or facilitator with legitimacy for all parties and the construction of "win/win" solutions or the provision of compensation for individual losers, for example by underwriting the cost of installing mitigation measures.

The experimental and multi-level nature of EPI in the EU has made it "highly contingent and complex", with a "situational quality" where its interpretation has varied between countries, policy domains and points in time [26] (p. 156). This has particularly been the case with "horizontal" or "inter-sectoral" forms of EPI [27,28], where it has required a "context-specific interpretation process" involving a wide range of actors and evolving over time as problems and understandings are gradually reframed [29] (p. 9). Most change appears to have been achieved at lower levels of administrative hierarchies, although progress has often been hampered by narrow remits and constrained budgets. This contrasts with "vertical" or "intra-sectoral" forms of EPI involving the development and application of new, more environmentally-friendly technologies and the promotion of the economic development opportunities that they bring. As already noted, the latter were fairly easily assimilated by Structural Funds programmes from the 1990s onwards; a lack of progress with the "inter-sectoral" 
form prompted the recasting of Structural Funds regulations to define environmental sustainability as a "horizontal priority" in the regulations for the 2000-2006 programme round.

\subsection{Environmental Policy Integration and the Structural Funds}

The 2000-2006 Structural Funds regulations and guidance stipulated that programmes should incorporate two HPs: "environmental sustainability" and "equality between men and women" [10,30-32]. These topics were framed in a way consistent with conventional Structural Funds approaches, requiring that economic development projects take the HPs into account, rather than mandating any specific or targeted activities. However, there were key disparities between the two. Thus, there was an explicit recognition that equal opportunities required positive action and mainstreaming, whilst environmental sustainability was presented partly as ensuring legislative or regulatory compliance and partly as taking environmental considerations into account.

At the EU-level negotiation stage for the 2000-2006 Structural Funds, development of EPI was still at an embryonic stage. Contemporary work by McCormick [33] (p. 261) found a "lack of universal or global understanding of the parameters of environmental policy within the EU institutions". This clearly influenced the inconsistent treatment of environmental issues in the Structural Funds guidance, in part reflecting the diversity of views within the environmental lobby, as well as the division of responsibility for environmental, economic and regional affairs between different Directorate Generals (DGs). Although DG Environment sought compromise by diluting "sustainable development" (SD) into "an equal balance between economic, social and environmental dimensions" [26] (p. 148), this still did not fit the dominant frame followed by economic interests in other DGs. Consequently, an attitude of passive resistance to the integration of SD into the Structural Funds was adopted by many of the economists involved in the negotiations. To overcome this, dedicated resources were allocated so that DGs Regio, Employment and Agri could jointly develop environmental policies specifically related to the Structural Funds [34,35]. The resulting recommendations were then presented as a separate package, with subsequent designation as one of the two "compulsory" HPs representing a belated attempt to boost their profile.

These recommendations were drawn from initial findings from twelve pilot projects run through existing Structural Funds regional programmes between 1997 and 1999. The aim was to explore methods of promoting sustainable development through practical applications that were compatible with economic regeneration goals, relevant to the needs of the area and acceptable to all those involved in the programme [36]. For most, the starting point was to address the breadth and complexity of sustainable development themes and, in doing so, to develop more clearly disaggregated and concrete objectives that connected with the interests of those involved and that made the advantages more tangible. The pilots also sought to develop better measurement and monitoring tools, to build partnerships and networks for sustainability, often through an external facilitator, to improve programme management procedures and the provision of advice and support for project applicants, and to link the financial assistance from the Structural Funds to other national, regional and local instruments for sustainability.

The synthesis of experience across the twelve pilots indicated the existence of four "pathways" through which the Structural Funds could promote sustainable development. First, actors within the 
region need to be engaged in a process of discussion and development (or "capacity-building"), with the aim of arriving at an agreed understanding of how sustainability goals could become an integral part of project design. This requires the involvement of one or more highly skilled and knowledgeable facilitators to bring actors together and to keep them engaged. Second, programme management tools and instruments need to be adapted so that sustainability requirements become more prominent. This applies to project selection criteria and the way in which they are applied, as well as to devising suitable monitoring indicators. Third, current gaps in the programme with respect to sustainability need to be identified and steps to fill them taken. This mainly focused on identifying programme measures with the greatest potential contribution and trying to ensure that this potential was maximised. Finally, the leading agencies and decision-makers need to be mobilised to develop a new programme focus centred on sustainability, as a precursor to the incremental diffusion of this approach across all of the actors involved. Again, this approach is predicated on the deployment of skilled and knowledgeable facilitators to disseminate the message.

The pilots were still in progress at the time when regional partnerships were working on their programme designs for the 2000-2006 round, and a full account of the experiences and lessons was not available until later in 2000 [37]. The extent to which these informed subsequent programme operation and implementation forms part of the empirical account presented in Section 4 below. From the evaluation evidence, however, it is clear that to take these insights on board, they would need intensive engagement with the topic. Thus, "the most successful regions (in the pilot) were proactive in their initiatives, engaging regional stakeholders in consultation exercises on sustainability objectives for the region and offering advice beyond the conventional bounds of technical assistance." [36] (p. 64).

\subsection{Interagency Working and the Role of "Champions"}

From the discussion so far, it is apparent that achieving progress in integrating environmental sustainability into Structural Funds programmes requires extensive inter-agency cooperation, in particular affording a central role to facilitators or "champions" who are able to bridge across different interests, approaches and viewpoints. Of course, there is a much wider literature within policy analysis that deals with these issues, especially in connection with the implementation at lower levels of the governance spectrum. Here, actors closely involved in service delivery and programme implementation tend to participate regularly in policy networks, which act as a source of learning [38-40]. Interactions between the key players are likely to occur frequently, and the tighter responsibility for achieving or exceeding target outputs focuses minds more clearly. In this context, cooperation and collaboration are likely to be facilitated.

Inter-agency co-operation is also more likely to occur where it is associated with mutual learning, trust and joint problem-solving in which scientific understanding and policy responses evolve together [41-43]. Unless political imperatives dictate otherwise, issues raised by external policy fields need to adapt to existing frames. As Peters [15] (p. 577) observes, this requires "reframing (of) contentious issues in a manner more agreeable to other participants." This may involve simplification down to core requirements, rephrasing using terminology more familiar to other participants or the provision of practical advice on how different types of agencies might address the issue. The existence or absence of such convincing "policy narratives" will either help or hinder the acceptance of the range 
of alternative courses of action on offer [44]. Even with repackaging along these lines, a degree of resistance may still emerge, making any modifications at best incremental and at worst superficial [45]. In this regard, the "transition spectrum" identified by Leigh [46] is worth mentioning. This delineated four possible reactions to pressures for change, namely denial, resistance, exploration and commitment. At the initial information sharing stage, the first two may lead to failure; the third and fourth imply a willingness to enter into negotiation.

The other important area of emphasis in this literature is on the part played by key individuals in introducing, translating and implementing new ideas into public practice. This role has been afforded several terms, the most common of which are "policy entrepreneur", "policy advocate" and "policy champion" $[47,48]$. These are "charismatic individuals who throw their weight behind a policy to help overcome indifference or resistance" [49] (p. 688). Their function is to act as a "coupler" between diverse actors and interests, which might involve a combination of creative, strategic, mobilising, administrative and evaluative activities [50]. While they can initiate the process by proposing ways in which ideas from other domains can be applied elsewhere, more typically, they excel at presenting ideas for prospective participants using their own terms, setting out the rationale and the likely benefits for each, as well as the disadvantages of alternative approaches. This can also involve using successful examples as a demonstration of what can be done and how it can be achieved. They may also lobby senior executives to secure high level support, as well as seeking to mobilise public opinion. Again, the precise mix depends on the structure and nature of the policy or programme in question and the wider political context in which it is set. Ultimately, such policy champions are mainly able to influence rather than to control the flow of events.

Roberts and King [47] found, in some cases, more than one entrepreneur at work in a given arena. Here, the key factor in policy outcomes is the nature of the interactions between them, as well as between champions and other policy actors during design and implementation. They called this "collective entrepreneurship", in which managing the meaning of a problem and linking it to an acceptable solution remained the core task. Their research also underlined the importance of personality type for the most effective champions, requiring an eclectic mix of characteristics, such as good intuition, strong analytical capabilities, critical thinking, problem-solving abilities and, above all, excellent interpersonal skills. Allen [51,52] similarly highlighted the growing importance of "facework" between welfare professionals and the personal relationships and 'deep trust' that this entails. The ability to build effective relationships, negotiation and brokering are key skills required by "boundary spanners" [2], professionals who work alongside colleagues from other policy domains. The role of policy champions at this stage thus becomes one of connecting people together to devise practical solutions and to mobilise the resources to implement them [53].

Of course, such champions do not always succeed in their endeavours. Much often depends on the existence of an appropriate "policy window" during which opportunities exist for the dissemination of new initiatives [54], on the strength and composition of "opposing forces" and the degree of leverage available over other players. Even with supposedly more flexible policy networks, an impasse might occur. Where actors have developed a shared understanding and perception of the key problems facing their domain, networks may become more akin to an epistemic community. In this situation, the group collectively sets the agenda, defines the frame and agrees with or resists changes in direction. As a network has no central organization or controlling force, at times of challenge (e.g., from external 
policy fields via the HPs), members' responses are unlikely to be standardised. At the same time, other research has illustrated how bargaining between different agencies becomes easier after a long period of working together. This is especially the case for organisations operating at local and regional scales, where more frequent interaction, much of it face-to-face, tends to be the norm, with the additional bonus that all parties are motivated to bring improvements to their geographical territories, rather than nationwide within their functional domains.

The wider literature on policy implementation echoes these conclusions concerning policy coordination. Thus, reviews by O'Toole [55,56] showed how recent research emphasises actor understandings, negotiations and bargaining, on the one hand, or disagreement and conflict, on the other. Similarly, Barrett reiterated the importance of communication and co-ordination in a "multiactor environment", the differences in values, interpretations and motivations between actors and agencies, the degree of autonomy held by those agencies, the scope for differential interpretation and the room for discretion in the use of policy instruments. Thus, "implementation (involves).... a policyaction dialectic involving negotiation and bargaining between those who seek to put policy into effect and those upon whom action depends." [57] (p. 253). In shifting attention away from organisational hierarchies and formal control mechanisms to power-interest structures, relationships and processes, this approach recasts implementation as "negotiated order."

From this perspective, the continued need for policy champions and "boundary spanners" is clear. While some champions will actually work on the front line, seeking to make the initiative beneficial for them and their clients in the manner of a "street-level bureaucrat" [58], others will act in a more advisory capacity. This will again involve presenting options to implementing agencies in terms understandable and acceptable to them, with the focus on ensuring activity on the ground. It will also entail a problem-solving role, assisting implementers to reorient their actions where their initial attempts have proven unsuccessful. Champions may also have to adopt a more defensive role against "outsiders" who seek to undermine or denigrate the efforts being made. As Berger [22] made clear, closer examination of this role and of the policy processes that surround it, such as bargaining over design, project formulation and implementation, is as important as analysing differences in power and power relations.

\section{Framework for Understanding Policy Coordination and Sources of Evidence}

Efforts to roll out more sustainable actions and practices amongst those whose main focus is not directly environmental contain strong echoes of the issues involved in policy coordination and innovation. Drawing on an extensive literature, the recent synthesis provided by Peters [15] offers a range of components that provide a broad framework for better understanding of the field. His initial observation is that policy coordination is generally addressed in two ways. On the one hand, it is seen as a "collective action" problem in which multiple actors have to overcome self-interest or ignorance of other possibilities in order to work with others as a means of improving overall performance. On the other hand, it is approached as an "ideational" problem, where the search is for an effective means for securing cooperation and collaboration between policy actors. Both place heavy emphasis on agency and the role of key players in the transaction. 
In essence, the two types of coordination problem are opposite sides of the same coin, rather than distinct alternatives. In this light, Peters' framework merges material from both approaches, following the "coalition formation" model devised by Thomson et al. [59]. The model posits that the process of coordination has five stages: information sharing; bargaining over proposals; bargaining over solutions; termination of bargaining; and implementation.

The first stage of information sharing is initiated by some form of "triggering event", which "forces (actors) to confer with each other" [15] (p. 573). The key actors involved identify the relevant players with whom to share information and select the range and type of information to be shared. Central questions include determining what is relevant (also referred to as "issue salience" in the corporate greening literature $[8,60]$ ), who would be appropriate participants in the search for coordination and how the information should be presented.

In the second stage of "bargaining over proposals", frequently the main body responsible for the policy area in question, or the agency charged with implementation, acts as the lead organisation pushing forward this part of the process. Depending on the context, there may be some compulsion that can be brought to bear on organisations otherwise reluctant to move away from their well-established paths of operation. However, this may well engender resistance in the form of power conflicts over perceived encroachment into that body's own expert territory. That said, any engagement in this exploratory negotiation suggests that each player has identified some potential benefits from the process.

The transition between negotiating about proposals and bargaining over solutions is frequently blurred; inevitably, both are discussed at the same time. Moreover, in some cases, the proposal is the solution. Nevertheless, the distinction is a useful one, as at some point participants do have to consider practical rather than hypothetical ways of moving forward. Since there tend to be multiple dimensions to any policy initiative, participants calculate what trade-offs can be made between them. They can make concessions on one aspect in return for gains (or less rigid requirements) in another, although these generally affect what they define as peripheral rather than core activities. According to Peters [15], another important consideration is the extent to which a policy issue can be disaggregated into a series of component parts. There is much more room for manoeuvring where the boundaries of what is acceptable are malleable than when the options are binary ("yes" or "no"). Shifting the focus to questions of implementation also provides an accessible means of finding some common ground for all participants. Another way forward would be to concentrate on areas where there is broad agreement and to park the more contentious issues until later (or to ignore them altogether). At the same time, a certain degree of conflict can be useful in enabling the bargaining to progress. For lead agencies, it may also be possible to deploy policy levers, such as additional funding or good publicity, as a means of securing other actors' buy-in. In the end, some conflicts may not be resolvable, but often a mutual need or commitment to engage with the policy keeps participants at the negotiating table. Continued interaction of this nature makes reaching a coordinated outcome much more likely.

Termination of bargaining covers the outcomes of the negotiation process, the culmination in crude terms being either the acceptance or rejection of the new idea. In reality, the likelihood is that some form of agreement will be reached, but it may or may not represent a compromise that is acceptable to all. For example, the lead agency may have largely dictated the shape of the ultimate solution, or agreement over the way forward may not have been unanimous. In either case, there is no guarantee that a stated commitment to a given approach will be followed up by concrete steps to put it into 
practice. After all, efforts at policy coordination are often characterised by an excess of rhetoric over meaningful action. For this reason, the incorporation of the new idea into a policy document or programme design does not necessarily mark the end of negotiation: the bargaining process will surely continue in the fifth stage, that of implementation. In fact, it may be more helpful to conceive of the coordination process as an iterative one, albeit with different players involved in each of the rounds. Thus, the process might go through a sequence comprising several phases, including high level production of policy guidelines, detailed design of the policy framework and instruments, local level selection of mechanisms for practical implementation and a whole series of feedback loops between all of the different aspects.

The rest of the article applies Peters' policy coordination framework as a heuristic device to present and assess evidence on the adoption and implementation of environmental sustainability and gender equality as horizontal priorities in the remit of the EU Structural Funds. Within this, the key concepts identified in the literature review are used to shed sharper light on important features of the process: in no particular order, these are policy champions, issue salience, policy narratives, boundary spanning, the transition spectrum and policy learning. Admittedly, deployment of Peters' framework restricts the account to a sequential ordering of a single-policy phase, in the process skating over the myriad interactions between actors at different levels before, during and after the programme period. However, it does allow a coherent and structured account of the process to emerge.

The account draws on a number of primary and secondary evidence sources. As well as published research and evaluation reports, including those on 2000-2006 Structural Fund programmes in the U.K., further detailed insights emanate from the author's direct involvement in three of these evaluations (Objective 1 in South Yorkshire; Objective 2 in the rest of Yorkshire and Humber; and Objective 3 across seven regions in England). This afforded extensive access to programme documents, committee minutes, project files and interview transcripts featuring national and regional policy-makers, programme officials, funding advisors and project managers. The analysis focuses on the extent to which projects funded by the Structural Funds in the U.K. incorporated aspects of environmental sustainability and gender equality into their design. A lack of suitable monitoring data makes it impossible to assess whether these commitments were met, still less what impact they had in terms of environmental or equality outcomes. Nevertheless, this is an important and germane area of investigation given the initial need to engage economic development actors in environmental thinking and the associated incremental learning role of environmental policy integration.

\section{Implementation of Sustainability and Gender Horizontal Priorities in U.K. Programmes}

\subsection{Information Sharing and Proposal Bargaining Round 1: Framing the Horizontal Priorities}

The multi-level nature of EU policy formulation and implementation means that there are usually several "triggering events" linked to successive supranational, national and regional/local rounds of decision-making. For the 2000-2006 Structural Funds, the first two were the decision to proceed with the programme (including the instruction to prepare the regulations) and the agreement with Member States over the areas designated as eligible for support. The latter was in itself the subject of 
lengthy bargaining $[61,62]$, though with little implication for the incorporation of environmental or gender concerns.

The other striking feature of the Structural Funds process was the close interweaving of information sharing and bargaining. In many cases, the nature of the information and the way it was presented were integral aspects of the negotiation process. Thus, the agreement for the regulations and guidance to incorporate the two horizontal priorities "equality between men and women" and "environmental sustainability" [10,30-32] emerged from parallel discussions among specially constituted sub-groups. For the gender theme, a high-level inter-service group assembled by the then Commissioner for Regional Policy, Monika Wulf-Mathies, enabled advocates to strategically present gender to fit the dominant policy frame of the EU [63]. In spite of the HP wording, this justified increased female labour market participation on the economic grounds of efficiency and competitiveness, rather than on the moral basis of promoting equality. Other opportunities enabled gender to be pushed firmly into the Structural Funds policy mix, including the wide-ranging review of regulations in readiness for the 2000-2006 programming period [64,65], well-developed activist networks to reiterate these strategic framing arguments [66,67] and the interventionist ethos of lead Structural Funds agencies, DG Regional Policy and Cohesion and DG Social Policy and Employment [68]. This narrow lens also left other avenues unexplored, among them the implications of cultural and religious differences between women across the EU, the gender pay gap and the consideration of how men's economic and social roles might be altered [69].

In many ways, this focus was also a reflection of the way in which the "parent" policy domain had originally been shaped. According to Wank [69], the EC's overall framing of gender followed an "equality/difference" perspective, rather than encompassing "diversity-oriented" or other approaches found in the international development sphere. The "equality/difference" perspective involves a duality emphasising "equal opportunities" on the one hand, and differences in the conditions and needs of men and women on the other. In the EC, this led to a homogenised definition of women's issues that foregrounded their economic position [70-73]. This smoothed the path to framing gender issues around the priority of increased employment and successfully inserting this perspective into the Structural Funds programme formulation. Interestingly, this did not include direct action to address pay disparities between men and women. This would no doubt have been very contentious and was "parked" in favour of the argument that improving women's skills and access to a wider array of opportunities would help to erode these gaps anyway.

In contrast, reaching agreement over how to address environmental sustainability was much more fraught, linked to the breadth and complexity of issues involved on the one hand, and to the diversity of views within the environmental lobby on the other. The aforementioned division of responsibility for environmental, economic and regional affairs between different DGs merely accentuated these fractures.

This also reflected the wider EU context, in which environmental policy integration (EPI) was still at an embryonic stage [23] and where it tended to follow the "weak" form of taking environmental considerations into account rather than placing them at the heart of decision-making [26]. In this way, sustainable development has frequently been an "add-on" to existing approaches, rather than posing a challenge to conventional thinking, as originally conceived. Essentially reaching any form of agreement for the Structural Funds was an achievement given the key difficulties facing EPI. These 
included wide variations in administrative capacity and expertise, poor coordination between Member States and the EC, weak network development and competing champions, a lack of a unifying framing device, and ineffective joint planning and priority setting [74,75].

\subsection{Proposal Bargaining Round 2: Reframing the Guidance}

Once the regulations had been issued and the areas eligible for support agreed, responsibility for taking the programme forward rested jointly with national governments as public expenditure controllers and dedicated regional partnerships with respect to detailed programme design and implementation. In the U.K., the first step involved repackaging and reinterpretation of the original EC guidance [30,31]. This was undertaken by small groups of civil servants drawn from a varying selection of government departments and related agencies. In England, representatives came from those ministries responsible for the disbursement of the money: Agriculture and Food; Environment, Transport and the Regions; and Work and Pensions (but not Energy) [76]. In contrast, the Scottish group included members from the Scottish Environmental Protection Authority (SEPA) and Scottish Natural Heritage (SNH), as well as the core functions in the newly-devolved administration [77,78]. According to an interview with a group member in London, a central rationale for providing duplicate guidance was to put the "more opaque European terminology into terms that regional partnerships could more easily understand". This included replacing the notion of HPs with the more commonly accepted term "cross-cutting themes" in England and Wales [76,79] and "horizontal themes" in Scotland [77].

This reframing also covered the two HPs, in terms of both title and scope. Thus, "equality between men and women" was shortened to "equal opportunities" in line with the EC's general guidance. While this could be said to encompass wider diversity concerns, the gender dimension remained most prominent. In contrast, while the term "environmental sustainability" was retained in England and Wales, it became "sustainable development" in Scotland. In the national guidance for the former, the emphasis was principally on matters directly affecting the environment, calling for actions to protect, manage and improve it. In the latter, the aim was to foster greater integration of sustainable action into all funded projects. This was based on the prior involvement of key Scottish environmental actors in a study to identify core sustainability criteria and practical guidance for different types of projects [78].

\subsection{Information Sharing and Solution Bargaining Round 1: Programme Structure and Content}

There were 19 separate Structural Funds programmes across the UK during the 2000-2006 period. The central feature of each was the Single Programme Document (SPD) or Community Support Framework (CSF). Each of these was drawn up through a dialogue between regional steering groups and national government ministries, with the EC hovering in the wings to endorse or prohibit certain courses of action. The balance of interests represented in the steering groups varied considerably between regions. Thus, the better resourced Objective 1 regions had a broad spread in terms of policy domains and public, private and voluntary sectors. This opened the door to actors in both environmental and gender lobbies (as well as other specific interest groups) to make their voices heard [80]. In contrast, economic development actors tended to dominate in the smaller Objective 2 areas and those organized around European Regional Development Fund (ERDF) allocations. 
SPDs were divided into two main sections: regional conditions (or problem analysis) and programme structure. The first comprised a mixture of in-house statistical analysis by civil servants and specially commissioned consultants' reports on particular topics, including gender and the environment $[81,82]$. This information was supplemented by evidence from earlier studies, as with sustainable development in Scotland [78], and submissions from other steering group members (e.g., an unpublished report on inequalities from the Black and Minority Ethnic Forum in Merseyside).

The second part of the SPD followed a prescribed structure of broad "priorities" and more specific "measures", with a set amount of financial resources allocated to each. These dealt with the standard concerns of economic development, such as business support, infrastructure provision, social enterprise and skills enhancement. As such, they may be considered as the "vertical" element of the programmes. As already stated, a few of these had direct relevance to environmental concerns, such as efforts to support the environmental technology industry or to promote farm diversification as a form of environmental protection. Only two SPDs in the U.K. (both in Scotland) explicitly incorporated the consideration of how the HPs could be addressed in each measure [83,84]; the norm was for HPs to be covered in a separate section of the programme documentation, an approach actively encouraged by the EC.

In terms of the two HPs practice was fairly diverse between the various regional steering groups. Some actually stuck to the original EC guidance, whilst others undertook their own reframing. One programme manager in the northeast commented that "we always have to remould (Structural Fund documents) to fit our circumstances, while sticking to the central messages." These variations emerged from each partnership's extensive negotiation sessions and reflected the different power balances within them. In most cases, the presence of gender and "social inclusion" champions ensured that the core principles of the equalities HP were retained. Indeed, all 19 programmes used the term "equal opportunities", as designated by national guidance, with the text closely following the rationales and courses of action framed by gender equality advocates throughout the process. This smooth transition also underscores the prominence that such issues had gained over previous years, not only in policy circles, but also in public perceptions.

With respect to "environmental sustainability", only a third of programmes (all in England and Wales) adopted the official term, while most Scottish programmes signed up to the broader concept of "sustainable development" (SD). The rest coined a wide range of alternatives, including "environmental protection", "environmental management" or simply "the environment". For the latter, the winning argument in bargaining reflected the dominance of economic and social interests, featuring a subtle reworking of the three-pronged conception of sustainable development that sees the economy, society and the environment as parts of an integrated whole [26]. For these programmes, the claim was that the economic development and social inclusion aspects were already covered by the "vertical" priorities and measures, leaving the environment as the only consideration of relevance for the HP. Compared to the relatively smooth acceptance of the gender theme, the lack of clarity around sustainability patently gave rise to considerable variation in interpretation.

National-level policy-makers and regional practitioners varied in their grasp of the potential benefits of the two HPs for regional economic prospects. As noted, in Scotland there was considerable buy-in from officials in the devolved government and its agencies around the environment and sustainability. Inter-organizational and inter-professional networks were already well developed. SEPA 
and $\mathrm{SNH}$ representatives on each regional group were active players in programme design and implementation $[78,85,86]$. In contrast, in England the national Objective 3 evaluation noted the lack of similar participation by national agencies at regional and project levels on how the two HPs could be put into practice, with the gap in terms of the environment seen as particularly acute [87].

This degree of autonomy and the influence of a wide range of lobbying interests in the regional steering groups meant that many programmes had more than the two HPs prescribed in the guidance. The most common addition was "social inclusion", adopted by a third of the programmes. This reflected disquiet with the EC's narrow gender remit in terms of labour market disadvantage and also underlined the confusion caused by the EC guidance asking for a wide range of other policy programmes (e.g., the European Employment Strategy) to be taken into consideration [88]. Designating further HPs offered a way of meeting these requirements without interfering with the "vertical" strands of the programme [89]. It is also instructive to note that an attempt to reframe "equal opportunities" into an all-encompassing "equalities" HP in South Yorkshire was overruled by the EC, leaving the programme with separate "gender equality" and "social inclusion" themes.

\subsection{Information Sharing and Solution Bargaining Round 2: Project Development}

The next stage involved inviting organisations to apply for funding for projects that would contribute to programme aims and objectives. This required clear and accessible information to be provided about what was required in terms of both eligible activities and the mechanics of the application process. Since most SPDs were long, detailed and cumbersome to use, programme management teams issued a host of supporting summary documentation in the form of priority prospectuses, supporting guidance and detailed development plans for particular geographic areas, like town centres. Most materials of this type attempted to pitch their contents in terms appropriate for their intended audience (that is, they aimed at providing a relevant "policy narrative"), but the sheer volume often made it hard for prospective grant applicants to find what they required. Some programmes also produced bespoke project development tools, like the Integrated Appraisal Toolkit used by Objective 2 in Northwest England. While many of these contained specific sections on how the two HPs might be addressed, in some cases, such potential links were completely absent [90,91].

However, over the first two years, most programmes had developed their own written advice and guidance on the HPs. These were issued as part of the standard application pack, with checklists to act as an initial planning tool. Although they generally avoided jargon and acronyms, generic materials provided meagre advances where they attempted to cover all eventualities. One way of avoiding this was to have separate information packs for different types of project. Good examples of this include the guide to integrating sustainability into human resource development proposals in Wales [92] and supplementary material on sustainable building design in South Yorkshire [93]. Nevertheless, at 45 and 30 pages, respectively, these also required some time to digest.

An important way of facilitating the dissemination of the HP messages was the recruitment of dedicated staff members (or "theme champions") to programme management teams. Around 40 percent of programmes adopted this route, although in some cases appointments were not made until the second or third year of implementation. Other programmes either added the responsibility to existing officers' portfolios or merely offered "signposting", putting applicants in touch with specialist 
organizations (as in Northeast England). The basis of the appointment of these "champions" also varied. Those joining programme teams were either direct employees or fixed-term secondees from partner organizations; those already in regional offices either covered all Structural Funds programmes (Objectives 2 and 3 and the Community Initiatives) or added the responsibility for Structural Funds to a similar environmental or gender remit across all regional programmes. Evaluation evidence indicated that recruitment of champions was not commensurate with the size of the task, with several respondents commenting that their effectiveness was limited by having to "spread themselves too thinly" [94-97].

Dedicated HP teams were mainly assembled by the better resourced Objective 1 and larger Objective 2 regions, where they were able to act exclusively as promotional "champions". In fact, this role took two distinct forms. The first involved more overarching ground preparation in the form of support to partnerships, delivery of training and awareness-raising sessions to managers and prospective applicants, contributions to guidance documents and appraisal systems, and attendance at a wide range of related meetings and workshops. This "facilitator champion" role is akin to that of the network co-ordinator identified as essential by Moss and Fichter [36,37]. In South Yorkshire, this post was filled by part-time appointees, on gender by a professor from a local university and on sustainability by a member of an environmental charity. The former reported that there was little difficulty in "selling" the message about improving women's access to the labour market to economic development actors looking to submit project proposals, as they could easily discern the benefits they would gain [98]. In contrast, by taking a rather purist line of obtaining future societal benefits for their own sake, the environmental "champion" struggled to persuade audiences of the relevance of sustainability issues for activities unrelated to adaptation mechanisms. In Scotland, a similar role was performed by the National Advisor on Sustainable Development, a full-time post jointly sponsored by SEPA and SNH to support all five Structural Funds programmes [78]. This afforded a strong degree of legitimacy, as well as continued participation in existing networks of key decision-makers. This deeper level of engagement was one factor in the early adoption of a pragmatic approach to the sustainability issue (see below). However, in Scotland there was no equivalent nationwide appointee for the gender equality theme. This was covered instead by specific programme-level staff.

The second form of "champion" role occupied more of a tactical position. Key tasks included strengthening guidance on the two HPs, rectifying misperceptions over the role of the "vertical" segments of the programme, providing practical hooks around which project designers could incorporate HP components, use of other projects as demonstrations, and participating in project appraisal $[80,94,99]$. They also helped applicants in other ways: in the words of one theme manager, one aspect of the role was "to try to develop levers to ensure not only that projects incorporated their aims, but also that they could tap into resources controlled by other programme managers".

Mostly, such "theme manager champions" were knowledgeable about sustainability or gender issues, but were by no means experts. They received no specific training on the implications and possibilities of the HPs, approaching implementation as much "on the fly" as project applicants. Many posts saw a relatively high turnover of personnel, sometimes because of time-limited funding or secondment agreements. New recruits would then have to carve out a fresh niche. There was more stability where regional-level government offices took the lead, but equally, such officers were also the most likely to be overstretched. Nevertheless, gender equality and sustainability champions both 
played a key "boundary-spanning" role, suggesting design amendments to projects at the appraisal stage and generally promoting HP aims. According to one interviewee, engagement with others involved in implementation enabled them "to develop relationships, which then underpinned their ability to assist with delivery at the sharp end".

Several programmes sought to support both the facilitator and theme manager champions by expert advisory groups, generally based on regional networks that were originally instrumental in shaping HP content in the first instance. Effective examples saw them transmuted into sources of practical advice, even working alongside others to formulate project ideas (e.g., the Gender Task Group in South Yorkshire). More typically, such groups were unwilling to move beyond their original lobbying role; according to several interviewees, this resulted in them becoming mere "talking shops" (e.g., the Environmental Sustainability Advisory Group, also in South Yorkshire). Again, the contrast between the simplified focus with respect to gender and the broad complexity and technological diversity of sustainability solutions is apparent.

The outcome in terms of bargaining stance for programme management teams therefore evolved into a pragmatic one, in the words of Macleod [78] (p. 324) focusing on "performance" rather than "conformance". This approach included the flexible accommodation of efforts to address the issues, use of appraisal criteria as an educative tool, and acceptance of any positive action as a welcome step forward. As the next section illustrates, the very framing of the "gender equality" HP made this a relatively small move for securing an acceptable degree of "gender mainstreaming" in project proposals; it involved greater compromise on both sides for the incorporation of aspects of sustainable development to be accepted.

\subsection{Termination of Bargaining and Implementation: Project Appraisal and Selection}

Structural Funds programmes feature a project-based approach to financial disbursement, involving a wide range of public, private or voluntary organisations submitting bids for support. These agencies generally had widely varying concerns, expertise, capacity and past experience. In practice, this widened the implementation net (and, hence, the bargaining process) across a myriad of actors and interests, albeit with negotiation generally occurring on a project-by-project basis. Having such a huge cast of implementers could only heighten the prospect of variability in the extent to which the HPs were addressed. It also meant that there was a high degree of mutual dependency in the bargaining process between the funder and the funding seekers.

All programmes deployed similar appraisal and selection systems as a decision-making tool, comprising a set of criteria to be addressed and a range of scores for assessing how well they had been met. At first, some systems omitted procedures for assessing how applications aligned with the HPs. Consequently, in some Objective 2 regions in England, the initial batch of funded activities was approved without having to show any contribution at all. Even where systems were comprehensive, they were not always applied in full. Thus, during the early funding rounds in Yorkshire and the Humber, Objective 2 region applicants could opt out of meeting "gateway" (or pre-selection) criteria, which included the contribution to HPs. Two-thirds of early applications followed this route [90].

Such practices further reflected the low profile given to the HPs by programme managers, at least at the outset [94]. Shortcuts were also rooted in a pragmatic need to kick-start programmes into action, 
especially in order to ensure a subsequent release of the "performance reserve", a proportion of the programme budget withheld until progress with spending commitments was demonstrated. This problem was compounded by the low weight given to each HP (in terms of marks available) in some scoring systems and the application of approval thresholds to aggregate assessment scores. Through this, many projects that scored zero against the HPs actually exceeded the overall threshold and, thus, gained approval. Interviewees in both London and the West Midlands complained about the appraisal and scoring process being "very mechanistic", particularly for Objective 3 funding, where the criteria had been set at national level.

As programme implementation developed, however, greater attention was paid to the HPs, particularly in refining administrative procedures and mechanisms to address them in more detail. Many project appraisal systems were adapted to include more explicit assessment of proposed projects' contribution to HP objectives. In some cases, the percentage of marks devoted to the HPs was increased to give them greater weight; in others, projects had to achieve a "pass" score for each aspect of the appraisal; and elsewhere, the HPs were used alongside other tests as "gateway" criteria in a two-stage process [93].

Although all appraisal systems were intended to be rational, objective and fair, their application underlined the difficulties of communicating the purpose of the HPs and the consequent recourse to pragmatism. As one selection panel member interviewed in Northwest England commented with regard to sustainability, "we are not sure what we should be looking for. If (it) is even mentioned, then the project will be given a 'middle of the range' mark". The same respondent stated that projects found it much easier to contribute to gender equality, via greater recruitment or training of women or the provision of childcare facilities. While this suggests that gender issues gained greater "issue salience" across the board, some applicants certainly admitted the benefits of "game-playing", with one stating that their resubmission simply contained "some more words in that section" to provide the "required narrative". Programme managers were well aware of these limitations: in the words of one interviewee, "this is all you can reasonably expect unless such issues are given greater weight in the selection process".

In essence, this attempt to marry broader environmental and gender considerations with economic development through the HPs prompted a battle for resources between competing interests. Project applicants seeking funding and officers in charge of mainstream programme delivery both responded to the HPs along lines that map neatly onto the "transition spectrum" typology of reactions outlined by Leigh [46]. Firstly, some completely rejected the need to address the HPs ("denial"), questioning them as "an irrelevance" in terms of their project activities and complaining about the complicated burden that they posed ("an impediment to action" or "a set of inconvenient hoops to jump through"). In such cases, it was clear that "issue salience" was low and that applicants had not been exposed to any convincing "policy narrative". While this applied to some extent to both HPs, it was especially prevalent with respect to environmental issues, with human capital projects under the European Social Fund (ESF) especially struggling to address them. This also echoes findings by Tummers [100] on the importance of "societal and client meaninglessness" as barriers for professionals in implementing new policies.

Secondly, many mounted "resistance" by claiming that such matters were already covered by their organisation's compliance with existing anti-discriminatory or environmental regulations, or via 
internal policies (e.g., on equal opportunities). Here, the tension between the "horizontal" and "vertical" dimensions of programmes came to the fore, with the mixture of "horizontal" mainstreaming across all measures and positive action in the form of specific "vertical" interventions, causing confusion [101]. Several respondents thought that the existence of explicit measures directly addressing gender equality and environmental sustainability issues meant that neither applied to the part of the programme under which they were applying. Consequently, many felt that they were merely paying "lip service" to HP aims and objectives.

Thirdly, as already mentioned, some actors tended to "play the game", outlining how their project addressed the HPs, but often providing little substance. Others admitted that they had made a strong case in their applications in order to access funding without having any real commitment to taking their proposals forward (that is, rhetoric rather than action). This clearly involved taking a calculated risk that their claims would never be properly scrutinised [89]. However, as some respondents conceded, even this "tokenism" gave them some exposure to HP ideas and potential benefits. Any engagement with the issues was likely to lead to some level of "exploration". Very often, this would be prompted by the work of the "policy champions", with gradual progress towards the acceptance of resource use efficiency being noted amongst some players [99]. Those that saw this process continuing into the future, perhaps in dialogue with a "champion", also appreciated that this could result in them contributing much more towards equality and environmental sustainability objectives. In other words, involvement in Structural Funds projects could serve as the start of a positive "policy learning" process.

Finally, many applicants did show "commitment" to contributing to HP aims, mostly through relatively simple or easily achievable actions. As already stated, most found it relatively straightforward to respond to gender equality requirements. However, often this was on a limited scale and involved little "exploration" of the issues, but rather sought to gain direct economic benefits or indirect competitive advantage. However, some respondents acknowledged that their experience of Structural Funds project design and implementation meant that they had embarked on a process of "policy learning" around gender issues, which might well develop more far-reaching provisions over time. Conversely, identification of environmental actions needed much more dialogue with "theme manager champions" and exposure to new information. The results may have been modest, involving increased materials recycling and improved energy efficiency, but according to interviewees such practices were generally adopted organisation-wide, rather than just in that specific project. Again, embedding such operational principles provided the basis for further "policy learning" and future extensions to mitigation mechanisms. In general, though, the keenest adopters remained those for whom the benefits were most transparent: for example, small community development projects incorporating renewable energy schemes in the Highlands and Islands of Scotland [80] and the adoption of accredited Building Research Establishment Environmental Assessment Method (BREEAM) benchmarks as a standard by infrastructure and construction projects in South Yorkshire [93].

\section{Conclusions}

Returning to the "research puzzle" set out in the Introduction, what does the comparative account of Structural Funds implementation in the U.K. tell us about the processes and constraints that help or hinder "organisational greening"? For a start, the contrast between the stripped-down explicitly 
economic focus of the gender equality HP and the more complex and opaque spread of the sustainability HP played a large part in the varying experiences and progress made by U.K. Structural Funds programmes with regard to these themes between 2000 and 2006. Beyond that, making headway relied on greater networking between programme managers, theme manager champions and economic development actors, presenting ideas in familiar terms and stressing economic rather than wider societal benefits. This was inevitably contingent on having time and resources to develop and to spread the message. Gender issues were received more readily, due to their exclusively economic framing, whereas the scale and nature of the changes apparently required in response to sustainability issues were often seen by economic development actors as an unwelcome challenge in their own area of expertise. This resulted in a greater likelihood of "denial" or "resistance" to such ideas. Ultimately, however, both HPs occupied an uneasy position within programmes as a set of "bolted-on" themes, a status reflected in programme content, administrative team structures, project guidance, application form layouts, appraisal and selection systems, monitoring and evaluation. As such, the use of HPs appears to be a rather blunt instrument for addressing wicked issues via mainstream economic development programmes.

Nevertheless, what also emerges from the account is that the HP method of addressing both gender and sustainability issues involves a series of diverse interactions between actors in different policy domains, repeated at each stage of the policy bargaining process from supranational formulation, through national/regional respecification to regional/local implementation. The outcome of these interactions is likely to vary according to the relative strength of policy networks at each level and in each domain; the extent to which dedicated resources are devoted to smoothing their path; the existence of effective "theme champions" and "boundary spanners" able to develop relationships that promote positive reactions; the extent to which they can meet demand for their services; and the availability of attractive practical options through which project designers can enhance the quality and value of their proposals. The need for those project applicants who take environmental issues on board to engage with them more actively as compared with the simplified gender equality focus may ironically prompt more thorough "exploration" and, thus, result in greater "commitment" on their part, and, in turn, in greater "policy learning" on the subject of sustainability.

The account also illustrates the merit of Peters' policy coordination framework as a heuristic device for untangling and understanding some of the complexities inherent in pursuing EPI in a multi-layered integrative programme, such as the EU Structural Funds. A key lesson is that the framework cannot be applied in rigid terms; rather, its five stages should be seen as flexible components which are likely to be closely interwoven at any given time. Moreover, working through the stages, in whatever combination, is seldom a "one-off" process: there are likely to be several iterations, some at the same level, some at different levels, as the policy proposal moves ever closer to implementation. For the Structural Funds, too, the process to date has been replicated twice since the programme round covered here, and this will have incorporated feedback, discussion and dissemination of lessons and experiences from across the EU. Although both the gender equality and environmental sustainability HPs have been retained, a key feature of the two subsequent programmes (2007-2013 and 2014-2020) has been the progressive shift of balance of sustainability actions between the horizontal and the vertical dimensions [102,103]. Indeed, providing support for the growth of a low-carbon economy, including assistance for companies to develop more sustainable ways of operating, is one of four "key investment 
priorities" for the EU Cohesion Policy in the new programme [104]. This availability of direct funding for sustainability projects is likely to make the work of environmental theme champions and the progress of policy learning much smoother.

\section{Acknowledgments}

The author would like to thank all those involved in the programme evaluation work drawn upon in the article, especially those who provided original materials; and colleagues within CRESR who have provided constructive comments on earlier versions of the paper. In both cases, they are too numerous to mention individually. Gratitude is also due to the two anonymous referees who both made a series of valuable suggestions to improve the structure and coherence of the article.

\section{Conflicts of Interest}

The author declares no conflict of interest.

\section{References}

1. Rittel, H.; Webber, M. Dilemmas in a General Theory of Planning. Policy Sci. 1973, 4, 155-169.

2. Williams, P. The Competent Boundary Spanner. Public Adm. 2002, 80, 103-124.

3. Gilley, K.; Worrell, D.; Davidson, W.; el-Jelly, A. Corporate environmental initiatives and anticipated firm performance: The differential effects of process-driven $v s$. product-driven greening initiatives. J. Manag. 2000, 26, 1199-1216.

4. Jabbour, C. Environmental training in organisations: From a literature review to a framework for future research. Resour. Conserv. Recycl. 2013, 74, 144-155.

5. Nasr, N.; Thurston, M. Remanufacturing: A Key Enabler to Sustainable Product Systems. In Proceedings of the 13th CIRP International Conference on Life Cycle Engineering, Leuven, Belgium, 31 May-2 June 2006; pp. 15-18.

6. Grob, S.; Benn, S. Conceptualising the adoption of sustainable procurement: An institutional theory perspective. Australas. J. Environ. Manag. 2014, doi:10.1080/14486563.2013.878259.

7. Rowe, A. Integrating Sustainability. Strateg. Mag. 2014, 31, 16-19.

8. Mair, J.; Jago, L. The development of a conceptual model of greening in the business events tourism sector. J. Sustain. Tour. 2010, 18, 77-94.

9. Pimenova, P. The Role of Support Programmes and Policies in Improving SMEs' Environmental Performance in Developed and Transition Economies. J. Clean. Prod. 2004, 12, 549-559.

10. Accenture Ltd. The UN Global Compact-Accenture CEO Study on Sustainability: Architects of a Better World; Accenture: New York, NY, USA; London, UK, 2013.

11. Commission for the European Communities. Eurobarometer Survey: How Green Are European SMEs? MEMO/13/1152; European Commission: Brussels, Belgium, 2013.

12. Commission for the European Communities. First Report on Economic and Social Cohesion; European Commission: Luxembourg, Luxembourg, 1996. 
13. Commission for the European Communities. Incorporating Equal Opportunities for Women and Men into All Community Policies and Activities; COM (96) 67 Final; Publications Office of the European Union (OPOCE): Luxembourg, Luxembourg, 1996.

14. Commission for the European Communities. Council Regulation (EC) No. 1260/1999 of 21 June 1999 Laying down General Provisions on the Structural Funds; Publications Office of the European Union (OPOCE): Luxembourg, Luxembourg, 1999.

15. Peters, B. Toward policy coordination: Alternatives to hierarchy. Policy Polit. 2013, 41, 569-584.

16. Commission for the European Communities. Third Environmental Action Programme: Towards Sustainability; European Commission: Luxembourg, Luxembourg, 1983.

17. Commission for the European Communities. Fourth Environmental Action Programme: Towards Sustainability; European Commission: Luxembourg, Luxembourg, 1987.

18. Commission for the European Communities. Fifth Environmental Action Programme: Towards Sustainability; European Commission: Luxembourg, Luxembourg, 1993.

19. Commission for the European Communities. Progress Report on the Implementation of the European Community Programme of Policy and Action in Relation to the Environment and Sustainable Development “Towards Sustainability”; COM (95) 624 Final; European Commission: Brussels, Belgium, 1996.

20. Liberatore, A. The integration of sustainable development objectives into EU policy-making: Barriers and prospects. In The Politics of Sustainable Development: Theory, Policy and Practice within the European Union; Baker, S., Kousis, M., Richardson, D., Young, S., Eds.; Routledge: London, UK, 1997; pp. 107-126.

21. Commission for the European Communities. Sixth Environmental Action Programme: Environment 2010: Our Future, Our Choice; COM (2001) 31 final; European Commission: Luxembourg, Luxembourg, 2001.

22. Berger, G. Reflections on Governance: Power Relations and Policy Making in Regional Sustainable Development. J. Environ. Policy Plan. 2003, 5, 219-234.

23. Commission for the European Communities. A Sustainable Europe for a Better World: A European Union Strategy for Sustainable Development, Commission's Proposal to the Gothenburg European Council; COM (2001) 264 Final; Communication from the Commission: Brussels, Belgium, 2001.

24. Lafferty, W.; Hovden, E. Environmental Policy Integration: Towards and Analytical Framework. Environ. Polit. 2003, 12, 1-22.

25. Lenschow, A. Variation in EC environmental policy integration: Agency push within complex institutional structures. J. Eur. Public Policy 2002, 4, 109-127.

26. Jordan, A.; Lenschow, A. Environmental Policy Integration: A State of the Art Review. Environ. Policy Gov. 2010, 20, 147-158.

27. Berger, G.; Steurer, R. National sustainable development strategies in EU member states: The regional dimension. In In Pursuit of Sustainable development: New Governance Practices at the Sub-national Level in Europe, Chapter 1, ECPR Studies in European Political Science; Baker, S., Eckerberg, K., Eds.; Routledge: Abingdon, UK, 2008; pp. 29-49.

28. Lundqvist, L. Implementation from Above: The Ecology of Power in Sweden's Environmental Governance. Gov. Int. J. Policy Adm. 2001, 14, 319-337. 
29. Baker, S.; Eckerberg, K. Introduction. In In Pursuit of Sustainable development: New Governance Practices at the Sub-national Level in Europe; Baker, S., Eckerberg, K., Eds.; ECPR Studies in European Political Science, Routledge: Abingdon, UK, 2008; pp. 1-25.

30. Commission for the European Communities. Vademecum: Plans and Programming Documents for the Structural Funds 2000-2006; Working Paper No. 1; European Commission: Brussels, Belgium, 1999.

31. Commission for the European Communities. The Structural Funds and Their Coordination with the Cohesion Fund: Draft Guidance for Programmes in the Period 2000-2006; Working Paper of the Commission; Wulf-Mathies, W., Flynn, P., Fischler, F., Bonino, E., Eds.; European Commission: Brussels, Belgium, 1999.

32. Commission for the European Communities. Mainstreaming Equal Opportunities For Women And Men in Structural Fund Programmes and Projects, New Programming Period 2000-2006; Technical Paper 3; Publications Office of the European Union (OPOCE): Brussels, Belgium, 1999.

33. McCormick, J. Environmental Policy in the European Union; Palgrave: Basingstoke, UK, 2001.

34. Environmental Resources Management. A Handbook on Environmental Assessment of Regional Development Plans and EU Structural Funds Programmes; European Commission: Brussels, Belgium, 1998.

35. Environmental Resources Management. Structural Funds and Environmental Assessment; European Commission: Brussels, Belgium, 1998.

36. Moss, T.; Fichter, H. Lessons in Promoting Sustainable Development in EU Structural Funds Programmes. Sustain. Dev. 2003, 11, 56-65.

37. Moss, T.; Fichter, H. Regional Pathways to Sustainability: Experiences of Promoting Sustainable Development in Structural Funds Programmes in 12 Pilot Regions; Office of Official Publications of the European Communities: Luxembourg, Luxembourg, 2000.

38. Marsh, D.; Rhodes, R. Policy Networks in British Government. Clarendon Press: Oxford, UK, 1992.

39. Rhodes, R.; Bache, I.; George, S. Policy Networks and Policy Making in the European Union: A Critical Appraisal. In Cohesion Policy and European Integration. Building Multi-Level Governance; Hooghe, L., Ed.; Clarendon Press: Oxford, UK, 1996; pp. 367-387.

40. Carlsson, L. Policy Networks as Collective Action. Policy Stud. J. 2000, 28, 502-520.

41. Haas, P. Introduction: Epistemic communities and international policy co-ordination. Int. Org. 1992, 46, 1-35.

42. Sullivan, H.; Skelcher, C. Working across Boundaries: Collaboration in Public Services, Government beyond the Centre Series; Palgrave-Macmillan: Basingstoke, UK, 2002.

43. Pollitt, C. Joined-up Government: A Survey. Polit. Stud. Rev. 2003, 1, 34-49.

44. Sutton, R. The Policy Process: An Overview; Working Paper 118; Overseas Development Institute: London, UK, 1999.

45. Keating, T.; Farrell, A. Problem Framing and Model Formulation: The Regionality of Tropospheric Ozone in the US and Europe; ENRP Discussion Paper E-98-11; Kennedy School of Government, Harvard University: Cambridge, MA, USA, 1998.

46. Leigh, A. Effective Change: Twenty Ways to Make it Happen; Institute of Personnel Management: London, UK, 1988. 
47. Roberts, N.; King, P. Transforming Public Policy: Dynamics of Policy Entrepreneurship and Innovation; Jossey-Bass: San Francisco, CA, USA, 1996.

48. Mintrom, M. Policy entrepreneurs in the diffusion of innovation. Am. J. Polit. Sci. 1997, 41, 738-770.

49. Rogers, E.; Peterson, J. Diffusion of Clean Air Ordinances in the Southwestern United States. Health Educ. Behav. 2008, 35, 683-697.

50. Roberts, N.; King, P. Policy Entrepreneurs: Their Activity Structure and Function in the Policy Process. J. Public Adm. Res. Theory 1991, 1, 147-175.

51. Allen, C. Joined-up working, welfare professionalism and the pursuit of the "pure relationship": A critical encounter with the sociology of trust. Hous. Theory Soc. 2003, 20, 2-14.

52. Allen, C. Desperately seeking fusion: On "joined-up thinking", "holistic practice" and the new economy of welfare professional power. Br. J. Sociol. 2003, 54, 287-306.

53. Matland, R. Synthesizing the Implementation Literature: The Ambiguity-Conflict Model of Policy Implementation. J. Public Adm. Theory Res. 1995, 5, 145-174.

54. Kingdon, J. Agendas, Alternatives, and Public Policies; HarperCollins: New York, NY, USA, 1995.

55. O'Toole, L. Research on Policy Implementation: Assessment and Prospects. J. Public Adm. Theory Res. 2000, 10, 263-288.

56. O'Toole, L. The Theory-Practice Issue in Policy Implementation Research. Public Adm. 2004, 82, 309-329.

57. Barrett, S. Implementation Studies: Time for a Revival? Personal Reflections on 20 Years of Implementation Studies. Public Adm. 2004, 82, 249-262.

58. Bardach, E. Getting Agencies to Work Together; Brookings Institution: Washington, DC, USA, 1999.

59. Thomson, R.; Stokman, F.; Torenvlied, R. Models of collective decision-making. Ration. Soc. 2003, 15, 5-14.

60. Bansal, P.; Roth, K. Why companies go green: A model of ecological responsiveness. Acad. Manag. J. 2000, 43, 717-737.

61. Armstrong, H. Regional Selective Assistance: Is the Spend Enough and Is It Targeting the Right Places? Reg. Stud. 2001, 35, 247-257.

62. Gripaios, P.; Bishop, P. Objective One Funding in the UK: A critical assessment. Reg. Stud. 2006, 40, 937-951.

63. Pollack, M.; Hafner-Burton, E. Mainstreaming gender in the European Union. J. Eur. Publ. Pol. 2000, 7, 432-456.

64. Bachtler, J. Reforming the Structural Funds: Challenges for EU regional policy. Eur. Plan. Stud. 1999, 6, 645-655.

65. Hall, R.; Rosenstock, M. Agenda 2000-The reform of EU cohesion policy. Eur. Plan. Stud. 2000, 6, 635-644.

66. Booth, C.; Bennett, C. Gender Mainstreaming in the European Union: Towards a New Conception and Practice of Equal Opportunities? Eur. J. Women's Stud. 2002, 9, 430-446.

67. Stratigaki, M. The Cooptation of Gender Concepts in EU Policies: The case of "Reconciliation of Work and Family". Soc. Polit. 2004, 11, 30-56.

68. Rees, T. Mainstreaming Equality in the European Union; Routledge: London, UK, 1998. 
69. Wank, C. Different Conceptualisations of Gender Mainstreaming in Different Institutional Settings: The specific interpretation of gender mainstreaming by the European Commission and the goal of gender equality. In Proceedings of the "International Institutions and Gender Equality" Panel of the ECPR Conference, Marburg, Germany, 21 September 2003.

70. Braithwaite, M. Mainstreaming Gender in the European Structural Funds. In Proceedings of the Mainstreaming Gender in European Public Policy Workshop, University of Wisconsin-Madison, Madison, WI, USA, 14-15 October 2000.

71. Bretherton, C. Gender mainstreaming and EU enlargement: Swimming against the tide? J. Eur. Publ. Pol. 2001, 8, 60-81.

72. Mazey, S. Introduction: Integrating gender-intellectual and "real world" mainstreaming. J. Eur. Publ. Pol. 2000, 7, 333-345.

73. Velluti, S. Implementing Gender Equality and mainstreaming in an Enlarged European Union: Some thoughts on prospects and challenges for Central Eastern Europe. J. Soc. Welf. Fam. Law 2005, 27, 213-225.

74. Burchell, J.; Lightfoot, S. The Greening of the European Union? Examining the EU's Environmental Credentials; Continuum Press: Sheffield, UK, 2001.

75. Schout, A.; Jordan, A. Coordinated European Governance: Self Organizing or Centrally Steered? Public Adm. 2005, 83, 201-220.

76. Office of the Deputy Prime Minister. Development of Structural Funds Single Programming Documents: Guidance to Regional Partnerships; ODPM: London, UK, 1999.

77. Scottish Executive. Structural Funds Programme Development: Guidance and Regulations; Scottish Executive: Edinburgh, UK, 1999.

78. Macleod, C. Integrating Sustainable Development into Structural Funds Programmes: An Evaluation of the Scottish Experience. Eur. Environ. 2005, 15, 313-331.

79. Wales European Funding Office. Guidance to Partnerships on Developing Structural Funds Programme Strategies; WEFO: Cardiff, UK, 1999.

80. Davies, S.; Bachtler, J.; Gross, F.; Michie, R.; Vironen, H.; Yuill, D. The Impact of Structural Funds Programmes in Scotland 1994-2006; European Policy Research Paper No. 60; European Policies Research Centre, University of Strathclyde: Glasgow, UK, 2007.

81. Newby, L. Objective 1 in South Yorkshire: Sustainability Review of Part 3 of the Programme Strategy; Forum for the Future: Leeds, UK, 2000.

82. Yeandle, S.; Buckner, L.; Gore, T.; Powell, R. Gender Profile of South Yorkshire's Labour Market; Objective 1 Programme Directorate: Rotherham, UK, 2000.

83. Ekos Ltd. East of Scotland Objective 2 Programme Mid Term Evaluation; Final Report; Scottish Executive: Edinburgh, UK, 2003.

84. Yellowbook Ltd. Mid Term Evaluation of the European Structural Funds Western Scotland Objective 2 Programme; Final Report; Scottish Executive: Edinburgh, UK, 2003.

85. Scottish Executive. Mid Term Evaluation of the Highlands and Islands Special Transitional Programme, Main Report (Final); Fraser Associates/European Policies Research Centre/Rural Development Company: Edinburgh, UK, 2003. 
86. Scottish Environment Protection Agency. Linking Sustainable Development to Regional Development: Learning Lessons from Scotland's European Structural Funds Experience; SEPA: Stirling, UK, 2004.

87. Haddrell, A.; Hardcastle, R.; Hersee, M.; Mooney, M.; Smith, Y. Mid Term Evaluation of the Objective 3 Community Support Framework for England/Gibraltar, Scotland and Wales; Final Report; Social Research Division, Information and Analysis Directorate, Department for Work and Pensions: London, UK, 2004.

88. Gore, T. The Open Method of Co-ordination and Policy Mainstreaming: The European Employment Strategy and Regional Conversion Programmes in the UK. Eur. Plan. Stud. 2004, 12, 123-141.

89. Ecotec Research and Consulting Ltd. Mid Term Evaluation of the London Objective 2 Programme 2000-2006; Final Report; Government Office for London and the Evaluation Steering Group: London, UK, 2003.

90. Leeds Metropolitan University; University of Hull. Mid Term Evaluation of the Yorkshire and Humber 2000-2006 Objective 2 Programme; Final Report; Yorkshire and Humber Structural Funds Evaluation Steering Group/Office of the Deputy Prime Minister: Leeds/London, UK, 2003.

91. Wells, P.; Booth, C.; Darlow, A.; Escott, K.; Gore, T.; Hanson, S. South Yorkshire Objective 1 Programme Mid Term Evaluation; Final Report; Yorkshire and Humber Structural Funds Evaluation Steering Group/Office of the Deputy Prime Minister: Leeds/London, UK, 2003.

92. Environment Agency Wales; Education and Learning Wales. Applicants Guide to Integrating Environmental Sustainability: HRD Regional Level Applications; ELWa and Environment Agency Wales: Caerphilly/Cardiff, UK, 2002.

93. Cohen, S. Is environmental integration possible in European funding programmes? Yorks. Humber Reg. Rev. 2008, 18, 13-14.

94. Ecotec. Cross-Cutting Themes Research Project (Objectives 1 and 3), Final Report C3008; Wales European Funding Office: Cardiff, UK, 2006.

95. Ekos Consulting (UK) Ltd. Mid Term Evaluation of the North East of England Objective 2 Programme: Final Report; Office of the Deputy Prime Minister: London, UK, 2003.

96. Fraser Associates/Regeneris. Mid Term Evaluation of the North West England Objective 2 Programme: Final Report; Office of the Deputy Prime Minister: London, UK, 2003.

97. Regeneris. Mid Term Evaluation of the Objective 1 Programme for Merseyside 2000-06; Office of the Deputy Prime Minister/Objective 1 Executive for the North West: London/Manchester, UK, 2003.

98. Gender Champion (South Yorkshire Objective 1). Personal communication, 2004.

99. GHK. The Thematic Evaluation on the Contribution of the Structural Funds to Sustainable Development, Volume 1: Synthesis Report; DG for Regional Policy and Cohesion, European Commission: Brussels, Belgium, 2002.

100. Tummers, L. Explaining the willingness of public professionals to implement new policies: A policy alienation framework. Int. Rev. Adm. Sci. 2011, 77, 555-581.

101. Taylor, S.; Polverari, L.; Raines, P. Mainstreaming the Horizontal Themes into Structural Fund Programming; IQ-Net Thematic Paper 10 (2); European Policy Research Centre: Glasgow, UK, 2001. 
102. Commission for the European Communities. Cohesion Policy in Support of Growth and Jobs: Community Strategic Guidelines 2007-2013; COM(205)0299; European Commission: Brussels, Belgium, 2005.

103. Dickinson, P.; Lloyd, R. European Social Fund Evaluation of Sustainable Development and Green Jobs; Research Report No. 756; Department for Work and Pensions: Sheffield, UK, 2011.

104. European Commission. EU Cohesion Policy 2014-2020: Targeting Investments on Key Growth Priorities, Information Note; DG Regional Policy: Brussels, Belgium, 2011.

(C) 2014 by the author; licensee MDPI, Basel, Switzerland. This article is an open-access article distributed under the terms and conditions of the Creative Commons Attribution license (http://creativecommons.org/licenses/by/3.0/). 